\title{
Persistencia y centralidad del desierto en el cine de Pier Paolo Pasolini
}

\section{Persistence and Centrality of the Desert in Pier Paolo Pasolini's films}

\author{
Pablo Corro Penjean \\ Instituto de Estética, Facultad de Filosofía, Pontificia Universidad Católica \\ de Chile. Santiago, Chile. \\ pcorro@uc.cl
}

\section{Resumen}

El texto identifica y analiza estéticamente la presencia icónica y argumental recurrente del desierto en los filmes de Pier Paolo Pasolini. Como sitio de exposición del origen propio y de puesta a prueba de la integridad de lo humano, el desierto de Pasolini se propone como un lugar ontológico. En este análisis, la poesía y la prosa del artista italiano contribuyen a delimitar las formas y funciones estéticas del desierto en su poética cinematográfica.

Palabras clave: Pasolini, desierto, Teorema.

\section{Abstract}

The paper identifies and aesthetically analyzes the iconic and argumentative recurring presence of the desert in Pier Paolo Pasolini's films. As a place of exposure of the origins of human integrity and its testing, Pasolini's desert is proposed as an ontological site. In this analysis, the poetry and prose of the italian artist contribute to define aesthetic forms and functions of the desert in his cinematography.

Keywords: Pasolini, Desert, Teorema. 
Pobre, Pasolini siempre se soñó viviendo y muriendo entre flores y árboles, entre prímulas y tilos; sin embargo, nunca pudo evitar el desierto. En el poema "El día de mi muerte", dice: "en una ciudad, Trieste o Udine, por una calle de tilos, cuando en primavera mudan de color las hojas, yo caeré muerto bajo el sol que arde rubio y alto y cerraré los párpados dejando el cielo en su esplendor" (La mejor juventud 34). En cambio, sobre el lugar cierto de la muerte del poeta, dice Benjamín Prado en su ensayo “Quién mató a Pasolini, cuál fue la razón?”:

El lugar donde mataron a Pasolini es de verdad deprimente. No está en la misma playa (de Ostia), como ya había supuesto, sino en una parcela vallada junto a la carretera en un páramo rodeado de suciedad, basuras, hierbas secas, que es la viva imagen del olvido. Un lugar para morir como un perro [...] aquella tierra baldía era ninguna parte, el sitio idóneo para acabar con alguien a quien todo el mundo desea ver muerto (24).

Pese a sus figuraciones ideales y fértiles que consisten en esa imagen de la "poesía en forma de rosa" eriazos deslumbrantes e hirvientes de Accattone (1961), esos tierrales que no se sabe si son calles o canchas en las barriadas del subproletariado romano, antes descritos en la novela Una vita violenta (1959). Hasta en los sueños de Accattone, su pandilla luce muerta, desnuda y cubierta de escombros sobre una tierra seca. En Mamma Roma (1962), la protagonista homónima, una prostituta retirada, y su recién recuperado hijo adolescente, Ettore ${ }^{2}$, miran desde su departamento el panorama de un supuesto porvenir auspicioso, de ascenso social: un llano en los extramuros de Roma, franqueado por soluciones habitacionales del tiempo del Duce y adornado por tierrales y manchones de pasto seco, donde el muchacho conocerá conjugados el amor y la vagancia, antesalas de la muerte. Por cierto, esos yermos urbanos no son propiamente el desierto, sino morfologías y topografías neorrealistas de la pobreza italiana de posguerra que, como márgenes de lo moderno, coinciden con los territorios del también inhóspito pero arcaico sur, con los parajes de Sicilia, de Catania, en la Terra Trema (1948) de Visconti o en Stromboli (1950) de Rosellini y aun en Il Gattopardo (1963), también de Visconti.

Si bien comparte el pensamiento político, reivindicativo del sur, como la alteridad de la Italia burguesa, y asume la sequedad como condición histórica y existencial de lo originario -en su caso, también como el vacío conveniente a quien se inicia con terror desde la literatura al cine, con la reserva del minimalismo blanco y rígido-, el desierto de Pasolini no es solo la afirmación de lo premoderno en tiempos del milagro económico, de la persistencia del tercer mundo en la Italia rubia, germánica, sino

1 Título de su decimoquinta publicación poética, Poesia in forma di rosa (1961-1964).

2 Interpretados por Anna Magnani y Ettore Garofolo, respectivamente. 
que es un paisaje cinematográfico de literal categoría ontológica, o sea, de exposición del origen y de consistencia de la identidad. El desierto es, siguiendo las categorías heideggereanas ${ }^{3}$ que distinguen fenoménicamente lo circundante en sus estadios antepredicativos y predicativos, la forma de la "tierra" más desprovista de "mundo", el sitio iconográfico expresivo de la determinación existencial originaria del ser arrojado; estado de la "derelicción" que Pasolini literaliza sinestésicamente con cierta prioridad de los planos en picado y con una figuración dramática del suelo.

El sentido religioso de esta ontología del desierto, religiosidad evangélica, histórica y literaria a la vez, en la versión de Mateo, adquiere reminiscencias genéticas irremediablemente postedénicas, en la medida en que la naturaleza ha sido reducida a pura adversidad geológica, a la hostilidad animal encarnada heráldicamente en las serpientes que se retuercen sobre el polvo grisáceo del Etna en Porcile (1969) o sobre los áridos suelos marrones de Marruecos en Edipo re (1967). Nos adelantamos si decimos que en Pasolini el desierto es la figuración de lo mismo, pero por ahora queremos sostener que cinematográficamente, es decir, en términos dramáticos e iconográficos, adopta siempre la misma forma. Ya sea en Il Vangelo secondo Matteo (1964), en Edipo re, en Teorema (1968) o en Porcile, siempre se trata de yermos encumbrados, casi siempre volcánicos: los faldeos del Etna en tiempos del reino de Sicilia bajo el dominio aragonés, en el siglo XV, o los mismos campos de lava del volcán siciliano figurando aquel desierto palestino del retiro de Cristo, o alguna cumbre del Atlas marroquí semejando el monte Citerón donde Edipo debía ser muerto por el pastor tebano o salvado por el pastor de Corinto. Unos y otros son sitios donde el encuadre general formaliza la dialéctica entre la tierra y el cielo como la tensión entre dos voluntades o, siguiendo las tipologías dramáticas de los planos de Deleuze, como una forma de imagen-percepción que expresa la existencia de un mundo por la convergencia provisional y predramática en el espacio de los cuatro elementos, que se suman al inferior y al superior a través de las nubes, los vapores y las nieblas que pasan, expresando el agua y el éter.

Este gran cuadro estéril pasa de la virtualidad vacía a la mínima figura de la peripecia, que es la de un sujeto que aparece y avanza de manera provocadora hasta el objetivo, donde se resiente inquisitivamente la personalidad del narrador observador o, como dice el propio Pasolini en su texto "Cine de poesía" (1970), hasta "dejar notar la cámara” (37). El desierto es un lugar vacío donde un hombre avanza levantando polvo. La imagen paradigmática de ese ícono fuerte es la escena de Il Vangelo secondo Matteo, en que Satanás interrumpe el retiro meditativo de Cristo, episodio de controversia teológica de Dios tentado por Dios. Como en los filmes sucesivos, la secuencia se compone de panorámicas que, antes de la entrada de Cristo o el Diablo

3 Cfr. Heidegger, Martin. Ser y tiempo. Traducción, prólogo y notas de Jorge Eduardo Rivera. Santiago: Universitaria, 1997. 
en escena, afirman la irreductible humanidad de cualquier paisaje vacío como paisaje visto, a través de movimientos contemplativos de cámara a los que se suman vistas del suelo y del cielo, donde el sol lucha con las nubes. El polvo que levanta la marcha del demonio, con los pies ocultos por la túnica, y que se integra a la costumbre evangélica, dramática e iconográfica de lo numinoso que enfrenta al hombre en el modo de lo disforme, natural y activo -tormentas de arena, zarzas incandescentes-, es una figura de mediación entre el cielo y el suelo en relatos de conciliación fatídica de voluntades: relato de Edipo, relato de Cristo, relato de los burgueses y el huésped, o de los burgueses y el ángel, o de los burgueses y el amor.

En Pasolini, el vacío del desierto, reflejo de la nada que la meditación también ansía como sitio monótono, es un paraje propicio para la figuración dramática del destino, para que las causalidades complejas adopten la manifestación formal de dos voluntades encontradas. En Edipo re, estas corresponden a las de los pastores cuyas marchas se enfrentan: por un lado, la del que huye de la misión criminal no cumplida, quien desobedece a Creonte; por el otro, la del que se apiada de un niño sin Padre y de un Padre sin hijo, el rey de Corinto.

Las causalidades trágicas son simples, las de Pasolini también: trágicas son las muertes mesiánicas de los subproletarios en Accattone, Mamma Roma y La Ricotta (1963). Con consecuencia formal, los movimientos de cámara del director son simples pero obstinados. Silvestra Mariniello señala que Pasolini se servía de la timidez dinámica de sus cámaras para hacer un cine hierático con apariencia formal de friso, con el estatismo propio del horror espacial del que transita creativamente de la literatura al cine. Sin embargo, no se puede olvidar los largos planos secuencia equidistantes y sincronizados con el avance de los protagonistas en -precisamente- sus primeros dos filmes, Accattone y Mamma Roma, travelling que según Bernardo Bertolucci, su primer asistente de dirección, se lo habría pedido a Tonino Delli Colli ${ }^{4}$ como un "carrito contra natura". Un plano secuencia familiar es el que (con cámara en mano) compone la imagen del pastor que avanza hacia el contracampo, siguiendo la trayectoria espacial del pequeño Edipo abandonado.

La prolongada e inquietante posición del personaje en el plano -siempre centrada aunque dinámica - relativiza el movimiento como cambio; para los bordes del encuadre, el movimiento es inmóvil o falso. Así como el personaje de Mamma Roma en la oscuridad plena de las calles prostibularias, sin referentes periféricos de cambio de posición, se despide infructuosamente de la noche en un movimiento falso y a través de un prolongado discurso digresivo y banal, el movimiento del salvador de Edipo parece cinematográficamente cuestionado y, con ello, también su facultad de torcer el destino. Esa cámara en mano que retrocede mientras el personaje avanza por el desierto es una visión objetiva afectada por la inquietud y el esfuerzo del sujeto que

4 Célebre director de fotografía del neorrealismo italiano y de Accattone. 
aparece en campo; afectada por la subjetividad del figurante activo. Es, por tanto, una visión semi-subjetiva, esa forma de coexistencia entre el yo y el otro que Pasolini suma al instrumental del cine de poesía y que Deleuze define como un "cogito fílmico", a la vez que lo señala como una estructura ejemplar de la "imagen-tiempo".

Sin duda, algo debe ser dicho sobre el llanto que mueve al pastor. En cualquier parte, pero más en el desierto, el sonido, y en este caso el llanto como voz no articulada en lengua, es un buen recurso para conocer el espacio. El grito es un rayo, una línea invisible en un campo indiferente. La conciencia cinematográfica de la voz prelingüística es, en el itinerario de Pasolini, la manifestación de una progresiva conciencia de la riqueza de lo sonoro, cuyo sentido estético había comenzado por la prioridad expresiva de las lenguas, los dialectos y los sellos sociales del habla (intereses propios del filólogo) y continuado en el estudio insistente de Bach, profanado o dignificado políticamente por su coexistencia con cantos afrobrasileros y cantos tradicionales rusos. La voz humana expuesta en la hostilidad del mundo como espacio abierto tiene sus variantes en la secuencia infinita de las prédicas de Cristo en Il Vangelo... y en la relación entre los ceremoniosos relatos procaces de los pervertidos de Saló o le 120 giornate di Sodoma (1975) y el zumbido aéreo, omnipresente de los bombarderos aliados que liberan la península y que representan la ejecución inminente de los facistas.

En Teorema, el desierto ha aparecido ya en la secuencia de créditos. La imagen de los faldeos volcánicos del Etna atravesados por nubes bajas precede sin sentido de contigüidad geográfica ni de relatividad dramática la escena del Padre, Pablo, según el libro homónimo, saliendo en su Mercedes Benz de su gran industria. La incertidumbre de ese nexo se revela cuando el Padre -al igual que cada uno de los integrantes de su familia- se abandona loco en el desierto, tras haber asumido con disposición de renuncia más o menos desesperada la partida del huésped: el ángel, protagonizado por Terence Stamp. Como el cumplimiento desquiciado, kierkegaardeano ${ }^{5}$, de la recomendación de la renuncia a todo que hace Cristo al joven rico, o Dios a Saulo el perseguidor, este pobre hombre poderoso, Pablo, deja la industria a los obreros, abandona la mansión, la familia, las vestiduras y se pierde tambaleándose y retorciéndose en el desierto como el caníbal de Porcile, como las culebras de todos los filmes, como una voz desgarrada en la soledad, tan desprovisto como el propio Edipo recién nacido. El avance del hombre desnudo desde el fondo del plano general hasta el primer plano atestado del rostro - el rostro profanado del actor Massimo Girotti $^{6}$, máxima cercanía sonora saturada por el grito de desesperación-, se propone en una sola duración y en un continuo espacial como la relatividad o dialéctica entre naturaleza y subjetividad, tal como en las secuencias iniciales el desierto y la fábrica habían manifestado la tensión entre naturaleza y mundo.

5 Cfr. Kierkegaard, Soren. Temor y Temblor. Barcelona: Labor, 1992.

6 Actor protagónico, seductor, amante fatal en Ossesione (1943); figura heroica, patriótica en Senso (1954), ambos, filmes de Luchino Visconti. 
Por su parte, el desierto de Porcile, aunque insiste en la exposición de la labilidad de toda cultura humana, entendida como sistema elevado (en parte) en función de la observancia de prohibiciones fundamentales - no comer animales impuros que se arrastran, no comer hombres- resulta complejizado simbólicamente por su relatividad dramática en un hiato de cinco siglos: desde la Sicilia gobernada por la Corona de Aragón hasta la Alemania políticamente neutralizada, económicamente reconstruida e interesadamente amnésica de 1968. La intriga de los millonarios productores de cerdos que guardan el secreto de su pasado nazi, así como los episodios de bestialidad que uno de ellos protagoniza con los animales (los mismos que luego lo devorarán) sugieren, en su reflexividad remota con el caníbal del Etna, la tesis de la bestialidad latente, epidérmica, del hombre y sobre todo del burgués, quien capitaliza en un ciclo de autodevoración los déficit ontológicos.

La categoría dramática ontológica del desierto pasoliniano como lugar de recuperación del sentido de sí mismo o de pérdida de la condición humana, como paraje y experiencia de exposición, alcanzó en la novela Teorema (1970) una precisión epifánica. Tal precisión se relaciona con la noción de unidad que, conforme al juego de las alusiones bíblicas del autor, puede representar tanto una categoría de lo teológico como una calificación espiritual de la burguesía. Una notoria omisión dramática del libro Teorema en el filme del mismo nombre es el capítulo 27, titulado "Los hebreos se encaminaron...". Lo único que tomó Pasolini para el filme de ese fragmento de referencias bíblicas, del peregrinar de los israelitas por el desierto, fue la imagen del desierto que insertó en las secuencias ya descritas. Ahora bien, ¿qué dice sobre el desierto y la unidad en ese pasaje del libro?

Los hebreos se encaminaron hacia el desierto. // Durante todo el día, desde el momento en que el horizonte se delineó contra el rojo de la aurora con sus dunas de roca, oscuras, chatas, o con sus dunas de arena, también oscuras, combadas, hasta la hora en que volvió a delinearse idéntico contra el rojo del crepúsculo, el desierto fue siempre igual. // Su inhospitalidad sólo tenía una forma. Se repetía invariable en cualquier punto donde se encontraran los hebreos, detenidos o en camino. // A cada milla el horizonte se alejaba una milla: así, entre el horizonte y la mirada, la distancia nunca cambiaba. [...] Así, al caminar por una inmensidad donde siempre parecían inmóviles; al encontrar de nuevo, una milla o cien millas después, la misma duna con los mismos pliegues idénticos dibujados por el viento; al no reconocer ninguna diferencia entre el horizonte septentrional y el meridional, o entre las ínfimas colinas oscuras de oriente y las de occidente [...] los hebreos empezaron a concebir la idea de la Unidad. // La percibieron el primer día, después de caminar en el desierto cincuenta millas; se sintieron invadidos por ella el segundo día, después de recorrer otras cincuenta millas sin que nada cambiase. Hasta que no tuvieron sino esa idea (Teorema 133-5). 
Esta formulación lírica y dramática del desierto como sitio de descubrimiento de la unidad se proyecta con un sentido esclarecedor sobre las escenas de El Evangelio según San Mateo, Edipo rey, Teorema y Porcile, si reconocemos que en ellas se exponen diversas posibilidades de puesta en riesgo de la integridad del ser, de la autonomía de la voluntad, de la consistencia de la libertad. Así, con la concurrencia dramática de tensiones dinámicas entre cielo, tierra, agua y aire, y con la asistencia figurativa de animales salvajes, las unidades propuestas - aun bajo la forma de su crisis- son las de Dios y hombre, libertad y necesidad, o voluntad y destino, hombre y naturaleza. La confianza de Pasolini en que el desierto es el ambiente, el mundo o la tierra -según su modulación semántica más o menos provista-donde estas dialécticas se pueden formular narrativamente, al conjugar virtualidades escénicas, dramáticas y existenciales de lo mítico, lo onírico, lo racional, lo moderno y lo arcaico; esa confianza, afirmamos, permite atribuirle al desierto una facultad privilegiada: la de reunir, articular y expresar, bajo sus causalidades heterodoxas, los elementos constituyentes de una lengua de poesía. En la manifestación cinematográfica del desierto se expresarían los componentes del fundamento irracional del cine, "o sea: todos sus elementos irracionales, oníricos, elementales y bárbaros, [que] han sido mantenidos bajo el nivel de la conciencia" ("Cine de poesía” 18); en el yermo tendrían expresión más nítida aquellos "arquetipos lingüísticos de los im-signos [...] las imágenes de la memoria y del sueño, o sea imágenes de «comunicación con nosotros mismos»" (19).

Para concluir, queremos identificar en el pasaje citado de Teorema aquella paradoja de movilidad inmóvil que experimentábamos en los motivos de los desplazamientos de los personajes por el desierto, particularmente en aquel avance hacia el contracampo, ejecutado por la cámara como travelling de retroceso y que calificamos como forma narrativa de la semi-subjetividad. Tal movilidad inmóvil relativiza la cualidad de cambio de lo dinámico y apunta a otro sello figurativo y dramático del cine de Pasolini. Aquel sello implica el pensamiento de la unidad y el enfrentamiento humano, que es la imagen, nítidamente presente en Accattone y en Teorema, de los luchadores como amantes, de los combatientes abrazados. En Teorema, la figura aparece en el estudio que hacen el huésped y Pedro, el hijo, del cuadro de Bacon: dos figuras; y por último, en Accattone a través de la pelea entre el protagonista y su cuñado.

\section{Referencias}

Accattone. Dir. Pier Paolo Pasolini. Act. Franco Citti, Franca Pasut, Silvana Corsini. Arco Film/Cino del Duca, 1961. Medio fílmico.

Bertolucci, Bernardo. "Raíces profundas". Pier Paolo Pasolini: Palabra de corsario. VVAA. Madrid: Círculo de las Bellas Artes, 2005. 13-16. Medio impreso.

Deleuze, Gilles. La imagen-tiempo. Buenos Aires: Paidós, 1996. Medio impreso.

---. La imagen-movimiento. Buenos Aires: Paidós, 2008. Medio impreso. 
Edipo re. Dir. Pier Paolo Pasolini. Act. Silvana Mangano, Franco Citti, Alida Valli. Arco Film/ Somafis, 1967. Medio fílmico.

Il Vangelo secondo Matteo. Dir. Pier Paolo Pasolini. Act. Enrique Irazoqui, Margherita Caruso, Susanna Pasolini. Arco Film/Lux Compagnie Cinématographique de France, 1964. Medio fílmico.

Mamma Roma. Dir. Pier Paolo Pasolini. Act. Anna Magnani, Ettore Garofolo, Franco Citti. Arco Film, 1962. Medio fílmico.

Mariniello, Silvestra. Pier Paolo Pasolini. Madrid: Cátedra, 1999. Medio impreso.

Pasolini, Pier Paolo. “Cine de poesía”. Pier Paolo Pasolini contra Eric Rohmer. Cine de poesía contra cine de prosa. Barcelona: Anagrama, 1970. 9-41. Medio impreso. ---. La mejor juventud. Trad., selección y prólogo de Delfina Muschietti. Buenos Aires: La Marca, 1996. Medio impreso.

---. Teorema. Trad. Enrique Pezzoni. Buenos Aires: Edhasa, 2005. Medio impreso.

Porcile. Dir. Pier Paolo Pasolini. Act. Pier Clémenti, Jean-Pierre Léaud, Alberto Lionello. I Film Dell'Orso/INDIEF /IDI Cinematografica/ CAPAC, 1969. Medio fílmico.

Prado, Benjamín. “¿Quién mató a Pasolini, cuál fue la razón?”. Pier Paolo Pasolini: palabra de corsario. VVAA. Madrid: Círculo de las Bellas Artes, 2005. 23-25. Medio impreso.

Teorema. Dir. Pier Paolo Pasolini. Act. Silvana Mangano, Terence Stamp, Massimo Girotti. Aetos Produzioni Cinematografiche/EIF, 1968. Medio fílmico. 